\title{
Homologous recombination and nonhomologous end-joining repair pathways regulate fragile site stability
}

\author{
Michal Schwartz, ${ }_{1}^{1}$ Eitan Zlotorynski, ${ }^{2}$ Michal Goldberg, ${ }_{1}^{1}$ Efrat Ozeri, ${ }^{1}$ Ayelet Rahat, ${ }^{1}$ \\ Carlos le Sage, ${ }^{2}$ Benjamin P.C. Chen, ${ }^{3}$ David J. Chen, ${ }^{3}$ Reuven Agami, ${ }^{2}$ and Batsheva Kerem ${ }^{1,4}$ \\ ${ }^{1}$ Department of Genetics, The Life Sciences Institute, The Hebrew University, Jerusalem, Israel 91904; ${ }^{2}$ Division of Tumor \\ Biology, The Netherlands Cancer Institute, 1066 CX Amsterdam, The Netherlands; ${ }^{3}$ Department of Radiation Oncology, \\ University of Texas Southwestern Medical Center at Dallas, Dallas 75390, Texas; USA
}

\begin{abstract}
Common fragile sites are specific loci that form gaps and constrictions on metaphase chromosomes exposed to replication stress, which slows DNA replication. These sites have a role in chromosomal rearrangements in tumors; however, the molecular mechanism of their expression is unclear. Here we show that replication stress leads to focus formation of Rad51 and phosphorylated DNA-PKcs, key components of the homologous recombination (HR) and nonhomologous end-joining (NHEJ), double-strand break (DSB) repair pathways, respectively. Down-regulation of Rad51, DNA-PKes, or Ligase IV, an additional component of the NHEJ repair pathway, leads to a significant increase in fragile site expression under replication stress. Replication stress also results in focus formation of the DSB markers, MDC1 and $\gamma \mathrm{H} 2 \mathrm{AX}$. These foci colocalized with those of Rad51 and phospho-DNA-PKcs. Furthermore, $\gamma \mathrm{H} 2 \mathrm{AX}$ and phospho-DNA-PKes foci were localized at expressed fragile sites on metaphase chromosomes. These findings suggest that DSBs are formed at common fragile sites as a result of replication perturbation. The repair of these breaks by both HR and NHEJ pathways is essential for chromosomal stability at these sites.
\end{abstract}

[Keywords: Common fragile sites; double-strand breaks; homologous recombination; nonhomologous end-joining; replication stress; genomic instability]

Supplemental material is available at http://www.genesdev.org.

Received February 16, 2005; revised version accepted September 12, 2005.

Common fragile sites are specific chromosomal loci that appear as constrictions or gaps on metaphase chromosomes from cells exposed to partial inhibition of DNA replication. Under these conditions, the general replication is slowed, but is not stalled. Unlike rare fragile sites, which are associated with expanded repeat sequences (Sutherland 2003), common fragile sites do not harbor such sequences and are an intrinsic part of the normal chromosomal structure, considered to be present in all individuals. The major inducer of common fragile sites is aphidicolin, an inhibitor of DNA polymerase $\alpha, \delta$, and $\varepsilon$ (Ikegami et al. 1978; Cheng and Kuchta 1993).

Early studies found a correlation at the cytogenetic level between chromosomal bands harboring common fragile sites and chromosomal breakpoints in tumors (Hecht and Hecht 1984; Yunis and Soreng 1984). Subsequently, molecular studies have demonstrated a role for common fragile sites in chromosomal instability in vitro

${ }^{4}$ Corresponding author.

E-MAIL kerem@cc.huji.ac.il; FAX 972-2-6584810.

Article and publication are at http://www.genesdev.org/cgi/doi/10.1101/ gad.340905. and in the occurrence of chromosomal rearrangements in tumors (Richards 2001; Arlt et al. 2003). Despite their inherent instability, common fragile sites are conserved in mice (Shiraishi et al. 2001; Krummel et al. 2002; Rozier et al. 2004) and primates (Ruiz-Herrera et al. 2004) and were even suggested to exist in yeast (Cha and Kleckner 2002; Lemoine et al. 2005).

Thirteen common fragile sites were cloned and characterized to date and the cytogenetic expression of each of these sites appears along a large genomic region ranging from several hundred kilobases to a few megabases (Arlt et al. 2003; Callahan et al. 2003; Denison et al. 2003; Ferber et al. 2003; Limongi et al. 2003; Zlotorynski et al. 2003; Rozier et al. 2004). Common fragile sites were found to be enriched in highly flexible AT-rich sequences (Mishmar et al. 1998, 1999; Zlotorynski et al. 2003), which were shown to have a high potential of forming secondary structures that could perturb the elongation of DNA replication along the fragile regions (Zlotorynski et al. 2003). Studies of replication time under normal growth conditions revealed a perturbed elongation of DNA replication along common fragile sites compared with nonfragile regions (Le Beau et al. 1998; 
Wang et al. 1999; Hellman et al. 2000; Palakodeti et al. 2004). The difference between fragile and nonfragile regions is further enhanced under partial replication inhibition. Under these conditions, in a substantial fraction of G2 cells, the fragile regions fail to complete their replication, indicating specific stalling of the replication fork along these regions (Le Beau et al. 1998). However, the molecular events that lead from replication perturbation to fragile site expression are still unknown.

Replication stalling may lead to replication fork collapse and hence to the formation of DNA double-strand breaks (DSBs) (Lundin et al. 2002; Saintigny et al. 2001). From all forms of DNA damage, DSBs are probably the most hazardous to the integrity of the genome. A failure to repair DSBs could lead to cell death or to chromosomal rearrangements (Khanna and Jackson 2001). In order to prevent the deleterious effects of DSBs, all organisms have evolved complex damage-response networks to detect and repair these lesions. The presence of DSBs is recognized by sensors, which transmit the signal to a series of downstream effectors through a transduction cascade to activate cell cycle checkpoints and induce DNA repair (Khanna and Jackson 2001; Jackson 2002).

There are two major DSB repair pathways, the homologous recombination (HR), which repairs the break using a homologous chromatid or chromosome, and the nonhomologous end-joining (NHEJ), which processes and ligates the DNA ends directly (Jackson 2002). These are distinct pathways and their function is complementary but partially overlapping (Mills et al. 2004). Replication-associated DSBs are repaired by both mechanisms, though the HR was suggested to play a more prominent role (Arnaudeau et al. 2001; Saintigny et al. 2001; Lundin et al. 2002).

A role for the activation of cell cycle checkpoints in common fragile site-associated gaps and constrictions has been recently demonstrated. The expression of common fragile sites was shown to be regulated by ATR (Casper et al. 2002, 2004), a protein kinase that regulates the replication-associated DNA damage response (Abraham 2001). Subsequently, BRCA1, a downstream target of ATR (Tibbetts et al. 2000; Xu et al. 2001, 2002), was found to affect fragile site stability via the $\mathrm{G}_{2} / \mathrm{M}$ checkpoint (Arlt et al. 2004). While writing this manuscript, a role in fragile site expression for two additional proteins was demonstrated, the structural maintenance of chromosome 1 (SMC1) and FANCD2, which are involved in DNA damage repair and checkpoint activation (Howlett et al. 2005; Musio et al. 2005).

These findings shed light on the role of cell cycle checkpoints in fragile site expression. However, it remains unclear if, under conditions that slow DNA replication, DSBs are formed at fragile sites and whether their stability is dependent on the DSB repair pathways.

Here we show that replication stress leads to formation of damage-induced nuclear foci of Rad51 and phospho-DNA-PKcs, key components of the HR and NHEJ DSB repair pathways, respectively (Jackson 2002). Furthermore, down-regulation of Rad51, DNA-PKcs, or the specific NHEJ ligase, Ligase IV (Weterings and van Gent
2004), leads to a significant increase in fragile site expression under replication stress. This indicates that the major DSB repair pathways are essential for the maintenance of chromosomal stability at common fragile sites. We further demonstrate nuclear focus formation of two proteins known to localize at DSBs, the phosphorylated form of histone H2AX ( $\gamma \mathrm{H} 2 \mathrm{AX})$ (Rogakou et al. 1998, 1999) and the mediator of DNA damage checkpoint protein 1 (MDC1) (Goldberg et al. 2003; Stewart et al. 2003). $\gamma \mathrm{H} 2 \mathrm{AX}$ foci colocalized with Rad51 and phospho-DNAPKcs foci. Importantly, $\gamma \mathrm{H} 2 \mathrm{AX}$ and phospho-DNA-PKcs foci were localized at expressed fragile sites on metaphase chromosomes. Hence, we suggest that conditions that only slow replication along the entire genome lead to DSB formation as a result of fork stalling and collapse at fragile sites. This activates the DSB repair pathways, which are required for the stability of these regions.

\section{Results}

The DSB repair proteins Rad51 and DNA-PKcs are recruited to damage-induced foci under conditions that induce the expression of fragile sites

In order to investigate the role of the DSB repair pathways in fragile site expression, we first analyzed the recruitment of Rad51 and DNA-PKcs, key components of the HR and NHEJ repair pathways, respectively, in cells treated with $0.4 \mu \mathrm{M}$ aphidicolin, a concentration used to induce the expression of common fragile sites. The HR pathway is involved in both the restart of stalled replication forks and the repair of DSBs induced by their collapse (Michel et al. 2001; Lundin et al. 2002). The NHEJ pathway is involved in DSB repair only (Critchlow and Jackson 1998; Lundin et al. 2002).

The Rad51 protein is recruited to sites of DNA damage, where it mediates the search for a homologous sequence in the homologous recombination process (Baumann and West 1998; Tarsounas et al. 2004). Immunofluorescence analysis in HeLa cells using Rad51 antibodies showed, under normal growth conditions, a diffused staining in $98 \%$ of the nuclei with less than five foci per nucleus (Fig. 1). Following aphidicolin treatment, discrete foci were observed in $>90 \%$ of the nuclei, with a mean of $22.5 \pm 1.7$ foci per nucleus (Fig. 1). The number of foci in treated cells was significantly higher than that found under normal growth conditions $(p<0.001)$. These results show that treatment with 0.4 $\mu \mathrm{M}$ aphidicolin leads to recruitment of Rad51 into damage-induced foci, which might indicate activation of the HR pathway.

DNA-PKcs is a protein kinase that is thought to tether broken DNA ends, to facilitate rejoining, and to recruit other factors of the NHEJ pathway (Burma and Chen 2004). DNA-PKcs undergoes autophosphorylation on Thr2609 in response to DSBs. The phosphorylated protein forms nuclear foci at the site of DNA damage (Chan et al. 2002). By using antibodies directed against the Thr2609 phosphorylated form of DNA-PKcs, we followed DNA-PKes activation and relocalization follow- 
A

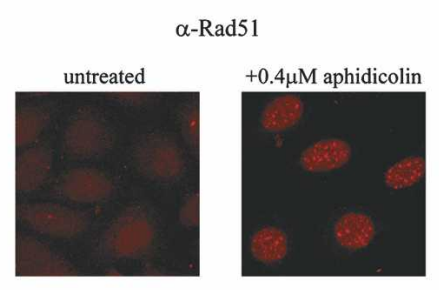

B

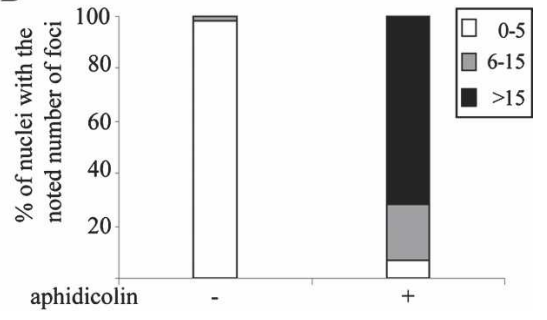

Figure 1. Rad51 forms foci following treatment with $0.4 \mu \mathrm{M}$ aphidicolin. (A) HeLa cells were treated with $0.4 \mu \mathrm{M}$ aphidicolin for $24 \mathrm{~h}$, fixed, and stained with anti-Rad51 antibodies $(\alpha-$ Rad51). Untreated cells were analyzed as control. (B) Number of Rad51 nuclear foci in cells treated with $0.4 \mu \mathrm{M}$ aphidicolin and in untreated cells. The data presented are based on at least two independent samples. ing treatment with $0.4 \mu \mathrm{M}$ aphidicolin. In untreated HeLa cells, most of the nuclei $(>95 \%)$ did not show any staining or showed few foci (less than five) (Fig. 2A,B). Following aphidicolin treatment, $>80 \%$ of the nuclei showed more than five foci, with a mean of $17.1 \pm 1$ (Fig. $2 \mathrm{~A}, \mathrm{~B})$. The number of foci in treated cells was significantly higher than that found under normal growth conditions $(p<0.001)$. These results suggest that this low aphidicolin concentration leads to DSB formation, probably due to the collapse of stalled replication forks. We further analyzed the phospho-DNA-PKcs focus formation in response to different aphidicolin concentrations (Fig. 2A,C). A concentration-dependent increase in the number of foci was detected. Following treatment with $0.1 \mu \mathrm{M}$ aphidicolin, $\sim 30 \%$ of the nuclei showed more than five foci, among which only $3 \%$ had $>30$ foci. Following treatment with $0.4 \mu \mathrm{M}$ aphidicolin, in $\sim 80 \%$ of the nuclei more than five foci were observed and the mean number of phospho-DNA-PKcs foci was threefold higher than that in cells treated with $0.1 \mu \mathrm{M}$ aphidicolin $(p<0.001)$. In cells treated with $6 \mu \mathrm{M}$ aphidicolin, a concentration that totally blocks DNA replication, $>40 \%$ of the nuclei showed $>50$ foci, a level that was not observed in the lower aphidicolin concentrations. Interestingly, the expression of common fragile sites in metaphase chromosomes also depends on aphidicolin concentration. Even a very low concentration of $0.1 \mu \mathrm{M}$ aphidicolin leads to fragile site expression, while treatment with $0.4 \mu \mathrm{M}$ results in a threefold increase in expression (Fig. 2D). The threefold increase in the number of phosphoDNA-PKcs foci between $0.1 \mu \mathrm{M}$ and $0.4 \mu \mathrm{M}$ aphidicolin is very similar to that found for fragile site expression in metaphase, indicating a correlation between these phenomena. Together, the results showing focus formation by Rad51 and DNA-PKcs indicate that both DSB repair pathways are recruited under conditions that induce the expression of fragile sites.

We then analyzed the possible interaction between the HR and NHEJ pathways, following conditions that induce fragile site expression. For this we performed coim-
A

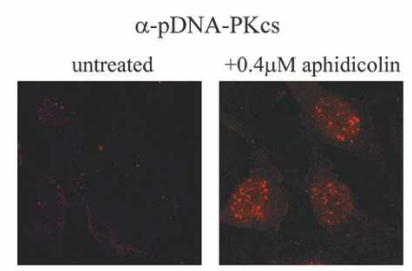

$+0.1 \mu \mathrm{M}$ aphidicolin
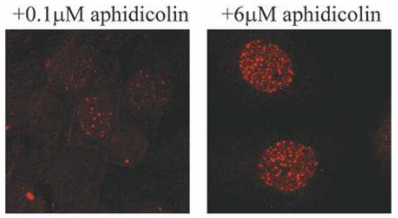

D

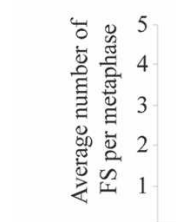

aphidicolin $(\mu \mathrm{M})$
B
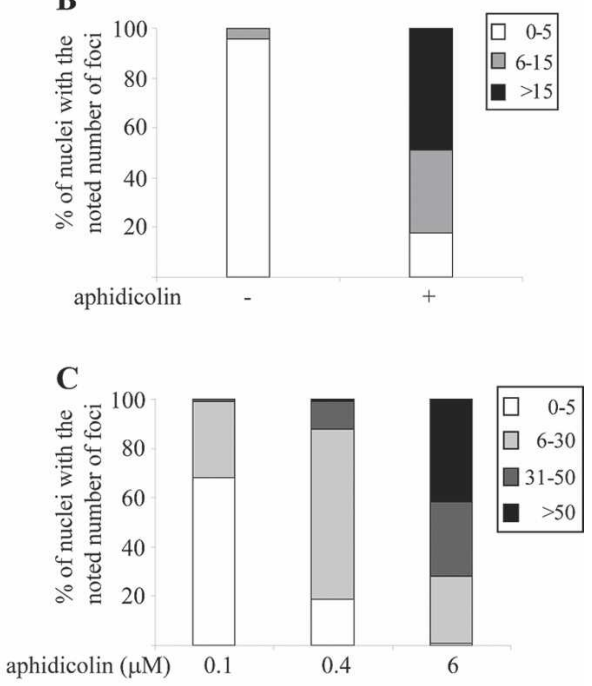

E

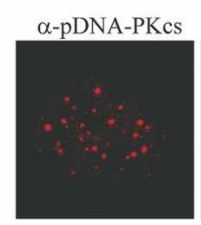

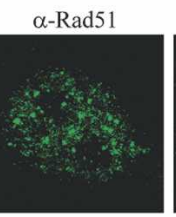

merge

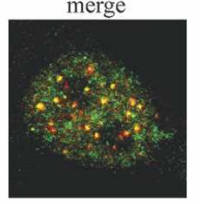

Figure 2. DNA-PKcs forms foci following aphidicolin treatment. (A) HeLa cells were treated with the indicated concentration of aphidicolin for $24 \mathrm{~h}$, fixed, and stained with antibodies against the DNA-PKcs, phosphorylated on Thr2609 ( $\alpha$-pDNA-PKcs). Untreated cells were analyzed as control. (B) Number of phospho-DNA-PKcs nuclear foci in cells treated with $0.4 \mu \mathrm{M}$ aphidicolin and in untreated cells. (C) Number of phospho-DNAPKcs nuclear foci in cells treated with the indicated aphidicolin concentration. Note that the categories are different from those in $B$ to allow comparison with the high number of foci obtained with $6 \mu \mathrm{M}$ aphidicolin. (D) Number of gaps and constrictions per metaphase in HeLa cells treated for $24 \mathrm{~h}$ with the indicated aphidicolin concentration. (E) HeLa cells were treated with $0.4 \mu \mathrm{M}$ aphidicolin for $24 \mathrm{~h}$, fixed, and costained with $\alpha$-pDNA-PKcs and $\alpha$ Rad51. The data presented are based on at least two independent samples. 
Schwartz et al.

munostaining using antibodies against both $\operatorname{Rad} 51$ and phospho-DNA-PKcs. In most nuclei three types of foci were observed (Fig. 2E): foci containing only Rad51 $(22 \% \pm 5.5 \%)$ or only phospho-DNA-PKcs $(40 \% \pm 8.5 \%)$ and foci in which the signal of both proteins colocalized $(38 \% \pm 7.5 \%)$. These results may suggest that the HR and NHEJ pathways can act to repair the same DSB.

\section{Rad51, DNA-PKcs, and Ligase IV repair proteins regulate fragile site stability}

We then analyzed the role of HR and NHEJ in fragile site expression by down-regulating the expression of the Rad51, DNA-PKcs, and Ligase IV genes. For this, HeLa and MCF7 cells were transiently transfected with the RNA interference pSUPER vector, which contained sequences directed against Rad51, DNA-PKcs, or Ligase IV. The transfection was performed using electroporation, which resulted in $\sim 85 \%$ efficiency (data not shown). First we analyzed the effect of down-regulation of Rad51. Western blot analysis showed reduction in Rad51 protein level in MCF7 cells transfected with pSUPER containing siRNA directed against Rad51 (pS-Rad51), compared with cells transfected with the pSUPER vector only (Fig. 3A). No reduction in Rad51 protein level was obtained in HeLa cells, despite the high transfection efficiency (data not shown). The reason for this is unclear; however, the lack of down-regulation could result from polymorphisms in the target sequence. Thus, further experiments were performed in MCF7 cells. Following 0.4 $\mu \mathrm{M}$ aphidicolin treatment, cells transfected with pSRad51 showed a significant increase in the level of gaps and constrictions (approximately twofold), compared with cells transfected with pSUPER $(p<0.01)$ (Fig. 3B). In these cells most $(60 \%)$ of the metaphases showed more than five gaps and constrictions, among which were metaphases with a high number of gaps and constrictions (>15), which were not seen in control cells (Fig. $3 \mathrm{~B}, \mathrm{Cl}$.

It is known that most chromosomal gaps and constrictions following aphidicolin treatment occur at fragile sites (Glover et al. 1984). To verify that the increase in gaps and constrictions in cells in which Rad51 was down-regulated is at common fragile sites, we measured the expression of the cloned common fragile sites FRA3B and FRA16D using fluorescent in situ hybridization (FISH) with specific probes. Rad51 down-regulation led to a fourfold $(p<0.01)$ and 4.5 -fold $(p<0.05)$ increase in the expression of FRA3B and FRA16D, respectively, under conditions of replication stress, compared with control transfections, (Fig. 3D). We further analyzed the effect of down-regulation of Rad51 expression under normal growth conditions. As can be seen in Figure $3 \mathrm{~B}$, a significant increase in the level of gaps and constrictions was observed in cells transfected with pS-rad51, compared with cells transfected with pSUPER $(p<0.01)$ (Fig. 3B). FISH analysis using probes from FRA3B and FRA16D regions revealed a significant increase in gaps and constrictions at these specific loci, $p<0.01$ and $p<0.05$, respectively (Fig. 3D). These results strongly suggest that under both normal conditions and replication stress, HR is required for the stability of fragile sites.

We then analyzed the effect of DNA-PKcs down-regulation on the expression of fragile sites. Western blot analysis showed reduction in DNA-PKcs protein level in both MCF7 and HeLa cells transfected with pSUPER containing siRNA directed against DNA-PKcs (pS-D-PK) relative to transfection with empty pSUPER (Fig. 4A). Following aphidicolin treatment, MCF7 cells transfected with pS-D-PK showed a significant increase in the level
Figure 3. Rad51 down-regulation by RNAi leads to increased common fragile site expression. (A) Western blot probed with $\alpha$-RAD51 in MCF7 cells transfected with pSUPER encoding siRNA directed against Rad51 (pS-Rad51). Transfection with the pSUPER plasmid (pS) was analyzed as control. Reduction in protein level was $90 \%$. (B) Number of gaps and constrictions per metaphase in MCF7 cells transfected with pSRad51 with or without treatment with 0.4 $\mu \mathrm{M}$ aphidicolin for $24 \mathrm{~h}$. Transfection with pS was analyzed as control. (C) Example of a metaphase from MCF7 cells transfected with pS-Rad51 showing a high number of gaps and constrictions $(n=15)$. The box in the bottom right is a magnification of the area marked in the picture. Arrows mark gaps and constrictions. (D) Frequency of fragile site (FS) FRA3B and FRA16D expression with or without $0.4 \mu \mathrm{M}$ aphidicolin treatment for $24 \mathrm{~h}$ in MCF7 cells transfected with pS-Rad51or pS. Error bars indicate the standard error. The data presented are based on at least two independent samples.
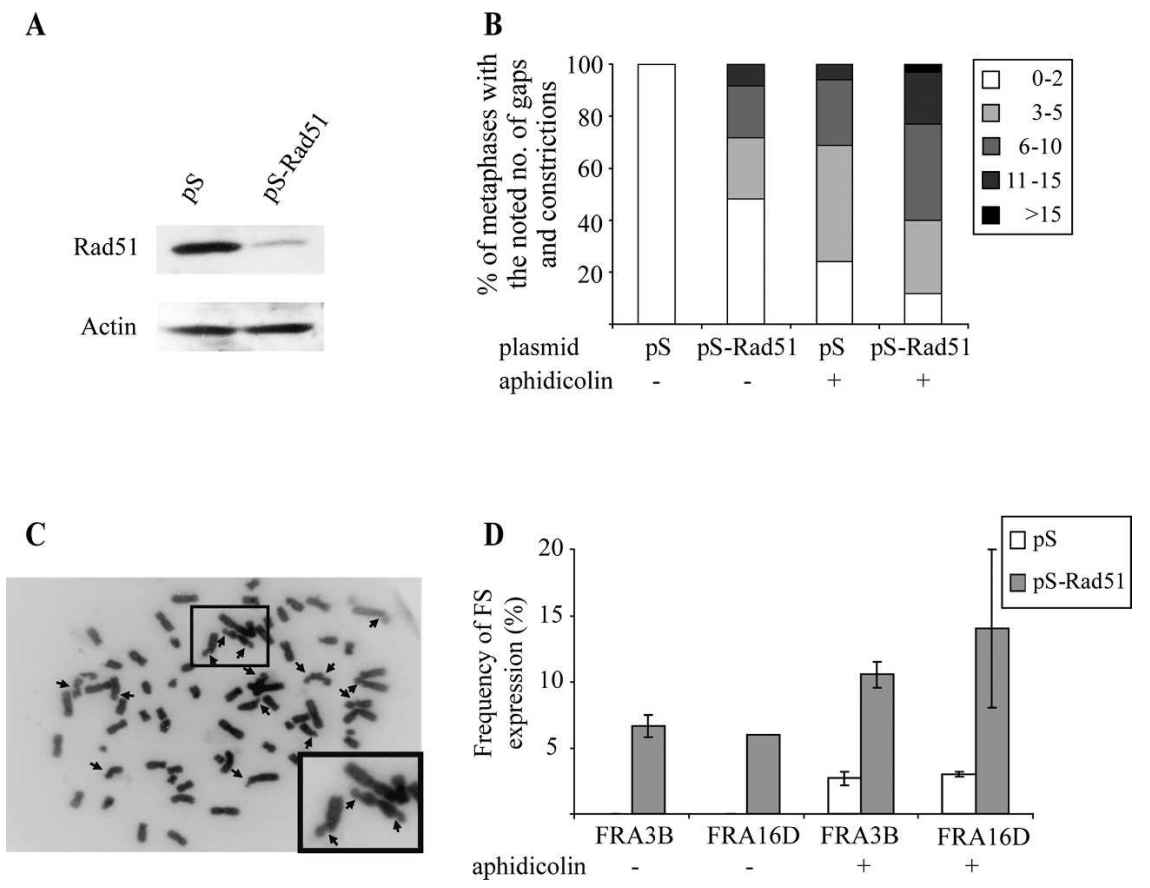
A

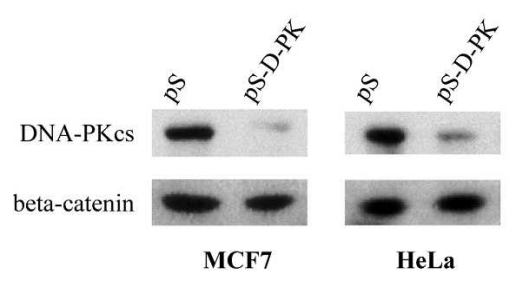

C
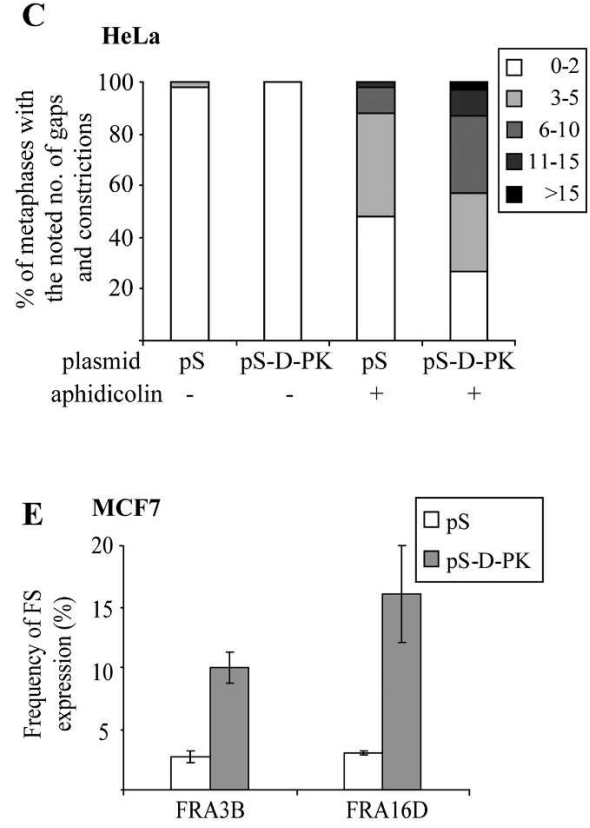

B $\quad$ MCF7

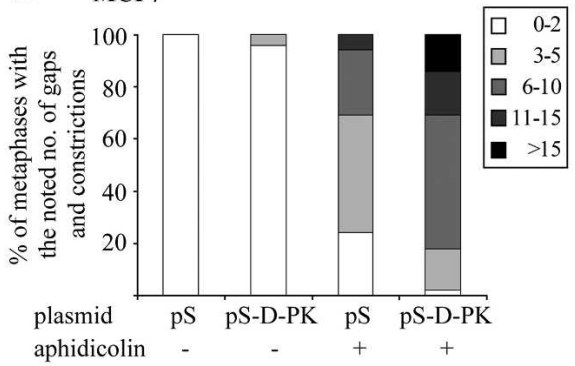

D

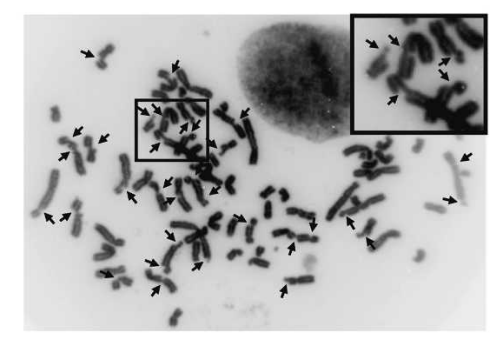

Figure 4. DNA-PKcs down-regulation by RNAi leads to increased common fragile site expression. (A) Western blot probed with $\alpha$-DNA-PKcs in MCF7 and HeLa cells transfected with pSUPER encoding siRNA against DNA-PKcs (pS-D-PK). Transfection with the pSUPER plasmid (pS) was analyzed as control. Reduction in protein level was $85 \%$ and $65 \%$ for MCF7 and HeLa cells, respectively. (B) Number of gaps and constrictions per metaphase in MCF7 cells transfected with pS-D-PK with or without treatment with $0.4 \mu \mathrm{M}$ aphidicolin for $24 \mathrm{~h}$. Transfection with the pS plasmid was analyzed as control. (C) Number of gaps and constrictions per metaphase in HeLa cells transfected with pS-DPK with or without treatment with $0.4 \mu \mathrm{M}$ aphidicolin for $24 \mathrm{~h}$. Transfection with the pS was analyzed as control. (D) Example of a metaphase from MCF7 cells transfected with pS-D-PK showing a high number of gaps and constrictions $(n=28)$. The box in the top right is a magnification of the area marked in the picture. Arrows mark gaps or constrictions. $(E)$ Frequency of fragile site (FS) FRA3B and FRA16D expression following treatment with $0.4 \mu \mathrm{M}$ aphidicolin for $24 \mathrm{~h}$ in MCF7 cells transfected with pS-D-PK. Transfection with the pS was used as control. $(F)$ The same experiment as in $E$, performed in HeLa cells. Error bars indicate the standard error. The data presented are based on at least two independent samples.

of fragile site expression (approximately twofold) compared with cells transfected with pSUPER $(p<0.001)$ (Fig. 4B). In MCF7 cells transfected with pS-D-PK, $>80 \%$ of the metaphases showed more than five gaps and constrictions, among which were $\sim 20 \%$ metaphases with $>15$ gaps and constrictions. In several of the metaphases the level was very high and reached $>25$ gaps and constrictions (Fig. 4B,D). In HeLa cells, a similar increase in the expression level was observed $(p<0.01)$ (Fig. 4C). The analysis of specific fragile sites following DNA-PKcs down-regulation in MCF7 cells showed a fourfold $(p<0.05)$ and fivefold $(p<0.05)$ increase in the expression of FRA3B and FRA16D, respectively, compared with control transfections (Fig. 4E). Similar results were found following down-regulation of DNA-PKcs in HeLa cells $(p<0.05$ for FRA3B and $p<0.01$ for FRA16D) (Fig. $4 \mathrm{~F})$. Down-regulation of DNA-PKCs expression under normal growth conditions did not lead to increased frequency of fragile site expression (Fig. 4B,D). Since fragile site expression was extremely low (0.5 fragile site [FS]/ metaphase) in cells following down-regulation of DNAPKcs under normal growth conditions, specific fragile site expression was not further analyzed.

Last, we analyzed the effect of down-regulation of Li- gase IV. Western blot analysis showed reduction in Ligase IV protein level in MCF7 cells transfected with pSUPER containing siRNA directed against Ligase IV (pS-LigIV), compared with cells transfected with the pSUPER vector only (Fig. 5A). As with the Rad51 downregulation, no reduction in Ligase IV protein level was obtained in HeLa cells; therefore further experiments were performed in MCF7 cells. Following $0.4 \mu \mathrm{M}$ aphidicolin treatment, cells transfected with pS-LigIV showed a significant increase in the level of gaps and constrictions (approximately twofold), compared with cells transfected with pSUPER $(p<0.01)$ (Fig. 5B). In these cells most $(80 \%)$ of the metaphases showed more than five gaps and constrictions, among which were metaphases with a high number of gaps and constrictions $(>15)$, which were not seen in the control cells (Fig. $5 \mathrm{~B}, \mathrm{C})$. The analysis of specific fragile sites following Ligase IV down-regulation in MCF7 cells showed a threefold $(p<0.05)$ and 2.5 -fold $(p<0.05)$ increase in the expression of FRA3B and FRA16D, respectively, compared with control transfections (Fig. 5D). It is worth noting that the increase in the expression of FRA3B and FRA16D following the down-regulation of the different genes was higher than the increase in the level of general 
Figure 5. Ligase IV down-regulation by RNAi leads to increased common fragile site expression. (A) Western blot probed with $\alpha$-Ligase IV in MCF7 cells transfected with pSUPER encoding siRNA directed against Ligase IV (pS-LigIV). Transfection with the pSUPER plasmid (pS) was analyzed as control. Reduction in protein level was $90 \%$. (B) Number of gaps and constrictions per metaphase in MCF7 cells transfected with pS-LigIV with or without treatment with $0.4 \mu \mathrm{M}$ aphidicolin for 24 h. Transfection with pS was analyzed as control. $(C)$ Example of a metaphase from MCF7 cells transfected with pS-LigIV showing a high number of gaps and constrictions $(n=18)$. The box in the top left is a magnification of the area marked in the picture. Arrows mark gaps and constrictions. (D) Frequency of fragile site (FS) FRA3B and FRA16D expression following treatment with $0.4 \mu \mathrm{M}$ aphidicolin for 24 $\mathrm{h}$ in MCF7 cells transfected with pS-LigIV or pS. Error bars indicate the standard error. The data presented are based on at least two independent samples.
A

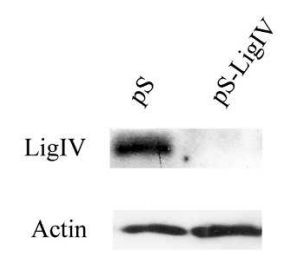

C

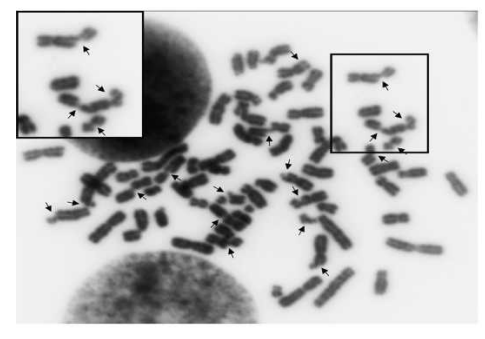

B

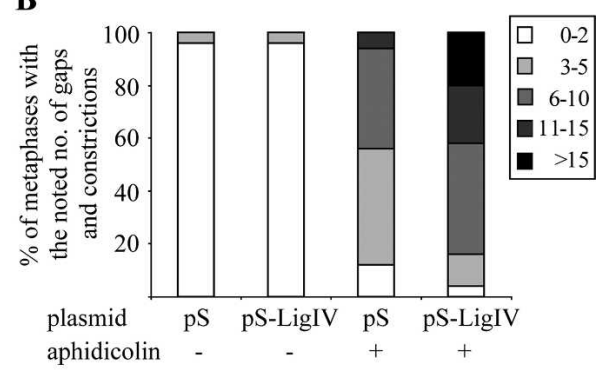

D

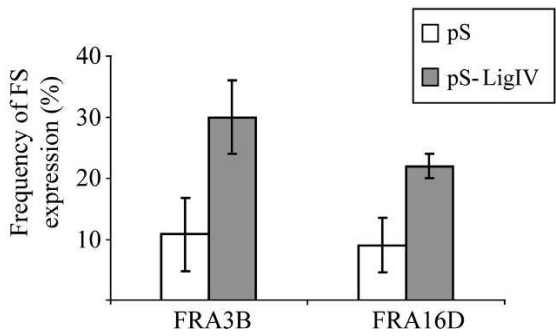

fragile sites, consistent with earlier reports that FRA3B and FRA16D are among the most frequently expressed fragile sites (Glover et al. 1984), which thus may pinpoint to their sensitivity to repair perturbation.

Down-regulation of Ligase IV expression under normal growth conditions did not lead to an increased frequency of fragile site expression (Fig. 5B), similar to the results obtained with DNA-PKcs under these conditions (Fig. 4B). This could result from incomplete down-regulation of DNA-PKcs and Ligase IV. Thus, in order to investigate this possibility, we performed the MTT assay to measure radiation sensitivity. In the absence of DSB repair factors, radiation sensitivity is expected to increase. Indeed, the analysis showed an increased radiation sensitivity following down-regulation of each of the NHEJ genes (Supplementary Fig. 1), indicating that the down-regulation of these genes was functionally effective. Hence it is more likely that under normal replication conditions, HR or other repair pathways can compensate for the deficiency of these NHEJ factors. It is important to note that our analysis was performed in HeLa and MCF7 cell lines, which might have abnormal checkpoint responses to unrepaired DNA damage that may affect their response to replication stress.

Altogether, the analyses of Rad51, DNA-PKcs, and Ligase IV demonstrate that the HR and NHEJ DSB repair pathways regulate the stability of fragile sites under replication stress.

\section{$\gamma H 2 A X$ and MDC1 form damage-induced foci under} conditions that induce the expression of fragile sites

To further investigate the formation of DSBs under conditions that induce the expression of fragile sites, we analyzed focus formation of $\gamma \mathrm{H} 2 \mathrm{AX}$ and MDC1, which are known to localize at DSBs (Rogakou et al. 1998, 1999; Goldberg et al. 2003; Stewart et al. 2003). Histone H2AX is a variant of histone $\mathrm{H} 2 \mathrm{~A}$, which undergoes phosphorylation in response to DSBs originating from diverse origins, including replication fork collapse. Histone H2AX phosphorylation occurs along a large region of several megabases around the site of damage, and hence is seen as discrete nuclear foci (Rogakou et al. 1998, 1999; Ward and Chen 2001). Phosphorylation of histone H2AX on Ser139 is crucial to the recruitment of other components of the damage response pathway to the damage site (Paull et al. 2000). Immunofluorescence analysis using antibodies directed against $\gamma \mathrm{H} 2 \mathrm{AX}$ was performed in HeLa cells following $0.4 \mu \mathrm{M}$ aphidicolin treatment. Under normal growth conditions most nuclei $(>85 \%)$ did not show any staining or showed less than five foci (Fig. $6 \mathrm{~A}, \mathrm{~B})$, consistent with the low level of DSBs formed during normal replication. Following aphidicolin treatment, $>95 \%$ of the nuclei showed $>15$ foci, with a mean of $58.2 \pm 2.9$ foci per nucleus (Fig. 6A,B). The number of foci in treated cells was significantly higher than that found under normal growth conditions $(p<0.001)$. Importantly, none of the aphidicolin-treated cells showed less than five foci, indicating that replication perturbation by low levels of aphidicolin leads to DSBs in all cells.

We further analyzed $\gamma \mathrm{H} 2 \mathrm{AX}$ focus formation in response to different aphidicolin concentrations (Fig. $6 \mathrm{~A}, \mathrm{C})$. A concentration-dependent increase in the number of foci was detected. The mean number of $\gamma \mathrm{H} 2 \mathrm{AX}$ foci following $0.4 \mu \mathrm{M}$ aphidicolin was 3.2-fold higher than that in cells treated with $0.1 \mu \mathrm{M}$ aphidicolin $(p<0.001)$. As in the case of DNA-PKcs, the increase in $\gamma \mathrm{H} 2 \mathrm{AX}$ foci between $0.1 \mu \mathrm{M}$ and $0.4 \mu \mathrm{M}$ aphidicolin is 
A
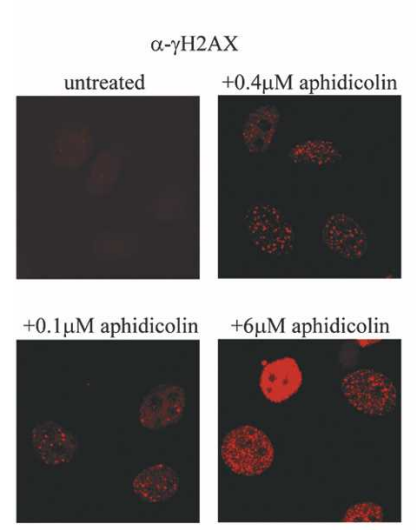

D
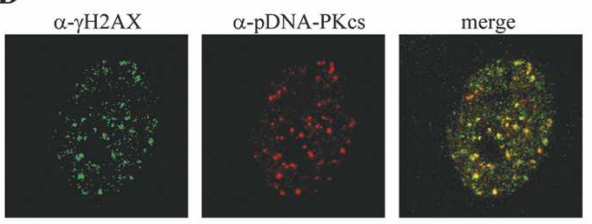

$\mathbf{E}$
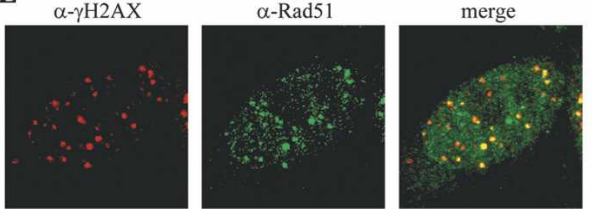

B
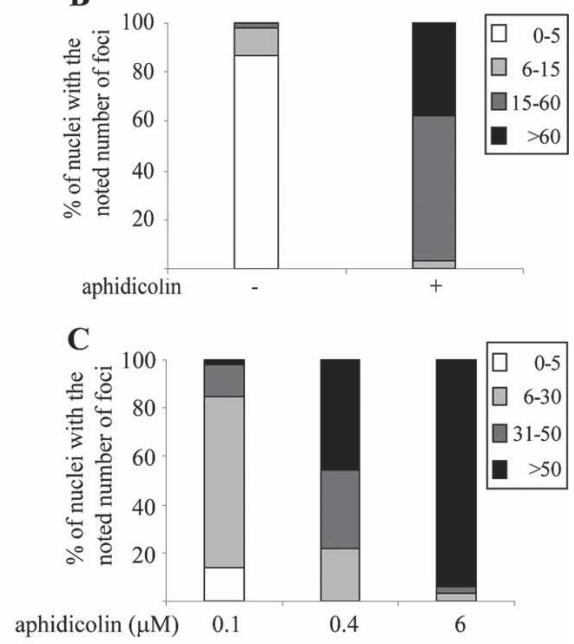

Figure 6. $\gamma \mathrm{H} 2 \mathrm{AX}$ forms foci following aphidicolin treatment. (A) HeLa cells were treated with the indicated aphidicolin concentrations for $24 \mathrm{~h}$, fixed, and stained with anti- $\gamma \mathrm{H} 2 \mathrm{AX}$ antibodies $(\alpha-\gamma \mathrm{H} 2 \mathrm{AX})$. Untreated cells were analyzed as control. $(B)$ Number of $\gamma \mathrm{H} 2 \mathrm{AX}$ nuclear foci in cells treated with $0.4 \mu \mathrm{M}$ aphidicolin and in untreated cells. $(C)$ Number of $\gamma \mathrm{H} 2 \mathrm{AX}$ nuclear foci in cells treated with the indicated aphidicolin concentration. Note that the categories are different from those in $B$ to allow comparison with the high number of foci obtained with 6 $\mu \mathrm{M}$ aphidicolin. (D) HeLa cells were treated with 0.4 $\mu \mathrm{M}$ aphidicolin for $24 \mathrm{~h}$, fixed, and costained with $\alpha-\gamma \mathrm{H} 2 \mathrm{AX}$ and $\alpha$-pDNA-PKcs. (E) HeLa cells were treated with $0.4 \mu \mathrm{M}$ aphidicolin for $24 \mathrm{~h}$, fixed, and costained with $\alpha-\gamma \mathrm{H} 2 \mathrm{AX}$ and $\alpha-\operatorname{Rad} 51$. The data presented are based on at least two independent samples. correlated with the increase in fragile site expression. Arresting DNA replication with $6 \mu \mathrm{M}$ aphidicolin led to massive phosphorylation of histone $\mathrm{H} 2 \mathrm{AX}$, as $94 \%$ of the nuclei showed $>50$ foci, of which $65 \%$ showed a uniform intense staining in which foci could not be counted. This indicates that DNA replication arrest leads to DSB formation throughout the entire genome, while conditions that only slow the replication lead to DSB formation in some genomic regions. We further analyzed the interaction of $\gamma \mathrm{H} 2 \mathrm{AX}$ with Rad51 or phospho-DNA-PKcs. The results showed that in all nuclei the vast majority of $\operatorname{Rad} 51(87 \% \pm 2.5 \%)$ or DNA-PKcs $(92 \% \pm 2 \%)$ foci colocalized with $\gamma \mathrm{H} 2 \mathrm{AX}$ foci (Fig. 6D,E). Since Rad51 and DNA-PKcs were shown to regulate fragile site expression, the colocalization of these proteins with $\gamma \mathrm{H} 2 \mathrm{AX}$ further supports our hypothesis that following replication stress, DSBs are formed at fragile sites.

We then analyzed in HeLa cells the response of MDC1, another protein that localizes at DSBs. MDC1 has been shown to form foci following irradiation-induced DSBs and replication stalling (Goldberg et al. 2003; Stewart et al. 2003; Xu and Stern 2003). Interestingly, MDC1 regulates DNA-PKcs autophosphorylation in response to DNA damage (Lou et al. 2004) and is essential for maintaining additional factors of the DNA damage response pathway at the damage site (Lukas et al. 2004). Immunofluorescence analysis using a specific antibody against MDC1 showed under normal growth conditions a diffused staining in $>90 \%$ of the nuclei, with less than five foci per nucleus (Fig. 7). In cells treated with $0.4 \mu \mathrm{M}$
$\mathbf{A}$

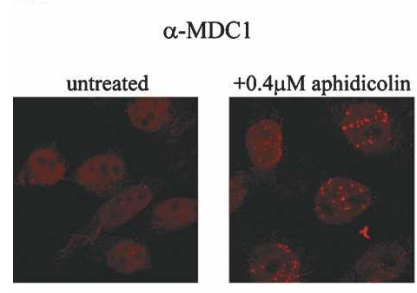

B

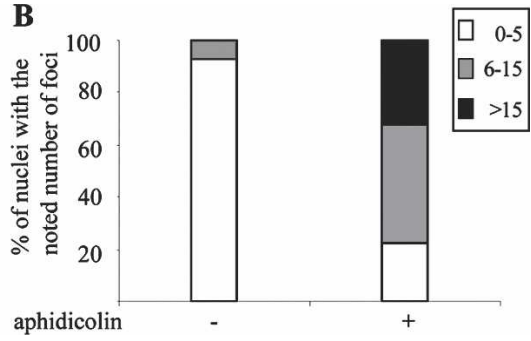

Figure 7. MDC1 forms foci following treatment with $0.4 \mu \mathrm{M}$ aphidicolin. (A) HeLa cells were treated with $0.4 \mu \mathrm{M}$ aphidicolin for $24 \mathrm{~h}$, fixed, and stained with anti-MDC1 antibodies ( $\alpha$-MDC1). Untreated cells were analyzed as control. $(B)$ Number of MDC1 nuclear foci in cells treated with 0.4 $\mu \mathrm{M}$ aphidicolin and in untreated cells. The data presented are based on at least two independent samples. 
aphidicolin, discrete MDC1 nuclear foci were observed in $\sim 80 \%$ of the nuclei, with a mean of $13 \pm 1.3$ foci per nuclei (Fig. 7). The number of foci in treated cells was significantly higher than that found under normal growth conditions $(p>0.001)$. These results, showing focus formation of both $\gamma \mathrm{H} 2 \mathrm{AX}$ and $\mathrm{MDC} 1$, indicate that aphidicolin treatment leads to DNA DSB formation.

\section{$\gamma H 2 A X$ and phospho-DNA-PKcs foci localize to expressed fragile sites at metaphase}

To examine whether the repair foci localize to fragile regions, we performed immunofluorescence using antibodies against $\gamma \mathrm{H} 2 \mathrm{AX}$ or phospho-DNA-PKcs and FISH using probes from the FRA3B region on cells following treatment with $0.4 \mu \mathrm{M}$ aphidicolin. Analysis of chromosome 3, in which FRA3B was expressed, revealed that in $68 \%$ of the chromosomes a signal of $\gamma \mathrm{H} 2 \mathrm{AX}$ was located on the gap (Fig. 8), while no signal of $\gamma \mathrm{H} 2 \mathrm{AX}$ was observed in chromosomes in which FRA3B was not expressed. A similar analysis was performed for phospho-
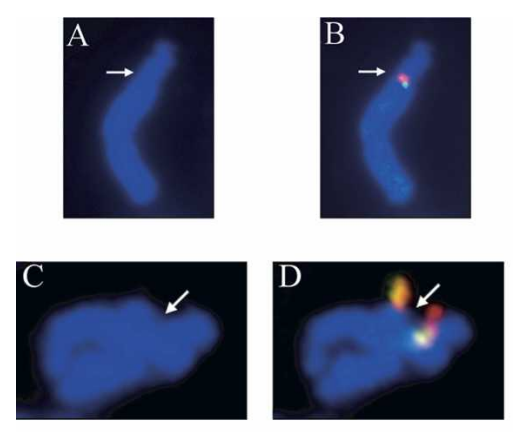

\section{$\mathrm{E}$}

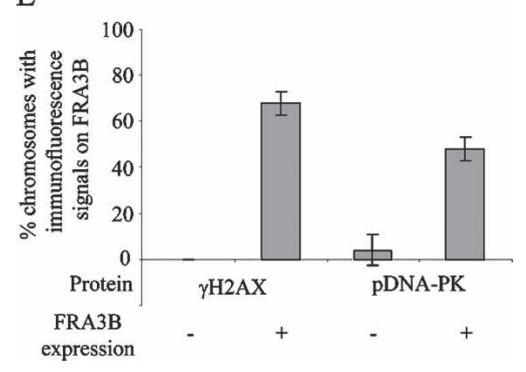

Figure 8. $\quad \gamma \mathrm{H} 2 \mathrm{AX}$ and phospho-DNA-PKcs foci localize to expressed fragile sites at metaphase. Chromosomes from HeLa cells treated with $0.4 \mu \mathrm{M}$ aphidicolin for $24 \mathrm{~h}$ were stained with anti- $\gamma \mathrm{H} 2 \mathrm{AX}$ or anti-phospho-DNA-PKcs and hybridized with a probe from the FRA3B region. (A) DAPI staining of chromosome 3 expressing FRA3B (arrow). ( $B$ ) The same chromosome showing a $\gamma \mathrm{H} 2 \mathrm{AX}$ immunofluorescent signal (red) and a FISH signal of a probe from the FRA3B region (green). (C) DAPI staining of chromosome 3 expressing FRA3B (arrow). (D) The same chromosome showing a phospho-DNA-PKcs immunofluorescent signal (red) and a FISH signal of a probe from the FRA3B region (green). (E) Quantitation of the localization of $\gamma \mathrm{H} 2 \mathrm{AX}$ and phosphoDNA-PKcs foci to the FRA3B region. Error bars indicate the standard error. The data presented are based on at least two independent samples.
DNA-PKcs that showed that on $48 \%$ of FRA3B gaps and constrictions phospho-DNA-PKcs signals were detected, while in only $4 \%$ of the chromosomes in which FRA3B was not expressed, a phospho-DNA-PKcs signal was found (Fig. 8). These results indicate that there is a specific interaction between DSB repair proteins and expressed fragile sites, providing evidence that repair proteins are recruited to DSBs in expressed fragile sites. The results further indicate that most expressed fragile sites represent regions undergoing repair at metaphase.

\section{Discussion}

Here we show that replication stress, which slows the general replication of the genome and induces the expression of common fragile sites, activates the DNA damage response pathway, leading to recruitment of the main DSB repair pathways, HR and NHEJ. We further demonstrate that these repair pathways are important for the stability of common fragile sites under these conditions. Common fragile sites are involved in different chromosomal rearrangements such as deletions, translocations, and viral integrations both in vitro and in vivo (Richards 2001; Arlt et al. 2003). The occurrence of all these events requires DSBs for their formation. Here we provide evidence that DSBs are indeed involved in the induction of gaps and constrictions at fragile sites under replication stress conditions. Previous studies suggested a role for checkpoint pathways and for DNA damage response pathways in the maintenance of fragile site stability. Our results demonstrate that a critical part of this response is the activation of DSB repair pathways, which are essential for the maintenance of chromosomal stability at common fragile sites.

Our first evidence was based on the nuclear focus formation by Rad51 and DNA-PKcs, major proteins of the HR and NHEJ DSB repair pathways, respectively, under conditions that induce fragility (Figs. 1,2). These pathways play an overlapping role in the repair of DSBs and the balance between them is not fully understood. DSBs that form at replication forks are repaired by both HR and NHEJ, although HR is thought to play a predominant role in such repair (Arnaudeau et al. 2001; Saintigny et al. 2001). A recent study by Chen et al. (2005) showed that NHEJ is preferentially activated by replication-associated DSBs. Previous studies showed that UV- and endonuclease-induced DSBs are also repaired by both HR and NHEJ, which can cooperate even at the same DSB (Richardson and Jasin 2000; Rapp and Greulich 2004). Our results show that under conditions that only slow DNA replication of the entire genome, both HR and NHEJ repair pathways are activated to maintain fragile site stability. The DSBs formed under these conditions may also be repaired by coupling these two pathways (Fig. 2E). The analysis revealed that a substantial number of phospho-DNA-PKcs and Rad51 foci colocalize. Further studies are required to investigate the kinetics of both repair pathways under these conditions.

The analysis of Rad51, DNA-PKcs, and Ligase IV 
showed an increase in fragile site expression under replication stress conditions, following down-regulation of either of these proteins (Figs. 3-5). This indicates that under these conditions, DSBs are formed at common fragile sites. Under normal replication, down-regulation of Rad51 led to a significant increase in fragile site expression, while down-regulation of DNA-PKcs or Ligase IV had no effect, suggesting that a deficiency in repair of replication-induced DSBs by NHEJ could be compensated by HR, but not vice versa. Interestingly, Allen et al. (2002) demonstrated that DNA-PKcs deficiency leads to an increase in DSB repair by HR, supporting that HR may partially compensate for NHEJ deficiency. Another possibility is that Rad51 down-regulation, but not DNAPKcs or Ligase IV down-regulation, may affect DNA replication per se. Further studies are required to investigate this hypothesis.

Since fragile sites are specifically sensitive to replication perturbation, we suggest that low levels of aphidicolin lead to replication arrest, and hence to formation of DSBs in these genomic regions, similar to the findings for the entire genome under prolonged replication arrest. This hypothesis is further supported by the formation of $\gamma \mathrm{H} 2 \mathrm{AX}$ and $\mathrm{MDC} 1$ foci, which indicates the formation of DSBs under replication stress (Figs. 6, 7). These results are consistent with a recent report by Musio et al. (2005) that showed $\gamma \mathrm{H} 2 \mathrm{AX}$ focus formation following $0.4 \mu \mathrm{M}$ aphidicolin in human fibroblasts.

Importantly, we have shown that $\gamma \mathrm{H} 2 \mathrm{AX}$ and phospho-DNA-PKcs repair foci localize to expressed common fragile site regions (Fig. 8). These results indicate that indeed DSBs form at common fragile sites following replication stress and are repaired by the DSB repair mechanisms. Interestingly, it was previously suggested that $\gamma \mathrm{H} 2 \mathrm{AX}$ functions as an anchor to hold the broken double-strand ends (Rogakou et al. 1998, 1999; Paull et al. 2000; Bassing and Alt 2004), implying that $\gamma \mathrm{H} 2 \mathrm{AX}$ foci represent unrepaired breaks. Thus, our results show that most gaps and constrictions seen on metaphase chromosomes at common fragile sites represent an ongoing damage that is still being processed at metaphase by the DNA damage response and the DSB repair pathways. The finding of expressed fragile sites in which no DSB repair foci were detected might represent regions in which DSB repair was accomplished yet their condensation is still incomplete.

The results presented here are highly significant for understanding the role that common fragile sites may play in chromosomal instability. Numerous molecular studies have shown that chromosomal breakpoints that drive genomic instability are located in common fragile sites (Arlt et al. 2003; Richards 2001). This includes amplification of the Met oncogene in gastric carcinoma located within FRA7G (Hellman et al. 2002), loss of the Fhit tumor suppressor gene located in FRA3B and of the WWOX tumor suppressor gene located in FRA16D in various tumor cells (Richards 2001; Arlt et al. 2003), and additional deletions (Arlt et al. 2002; Denison et al. 2003) and translocations (Wilke et al. 1994; Krummel et al. 2000; Fang et al. 2001) at these and other fragile sites.
Additionally, integrations of the human papilloma virus in cervical carcinoma were found to occur at common fragile sites (Wilke et al. 1996; Thorland et al. 2000, 2003). The results presented in our study indeed demonstrate the occurrence of DSBs at fragile sites following replication stress. During in vivo tumorigenesis, exposure of cells to physiological environmental factors that interfere with DNA replication, such as hypoxia; deregulation of the nucleotide pools; and treatment with cytotoxic drugs might induce fragile site expression and chromosomal rearrangements arising from DNA breakage at these sites.

Thus, we propose a model for the molecular events leading from replication stress to the induction of common fragile sites. Fragile sites are genomic regions that are significantly more sensitive to replication perturbation than other regions in the genome. The reason for their sensitivity is unknown; however, it was shown that the fragile regions are enriched in AT-dinucleotide runs, which may lead to perturbed elongation of DNA replication due to their high DNA flexibility and their potential to form secondary structures (Zlotorynski et al. 2003). Therefore, under conditions of replication stress, which only slow the replication of the entire genome, the replication forks tend to stall and collapse at the fragile regions, leading to DSB formation. The stalled replication forks are recognized by the DNA damage response mechanism, which activates cell cycle checkpoints through the ATR cascade and other proteins, including histone H2AX, BRCA1, SMC1, MDC1, and FANCD2. In parallel to the checkpoint activation, the DNA repair pathways are recruited to the damage sites. The stalled forks may then be restarted by the HR pathway or, in the case of fork collapse and DSB formation, repaired by the HR and/or NHEJ pathways. Most of these replication-induced lesions are repaired and hence the chromosome structure at metaphase is normal. However, in cases where the lesion fails to be repaired and persists into mitosis, or if the repair occurs late in $\mathrm{S}$ phase or in G2, the chromatin condensation of a large region will be disrupted and hence gaps and constrictions will appear in metaphase at the fragile regions. According to this model, deficiencies in genes of the DNA damage response cascade might result in a less efficient repair and greater chromosomal instability at fragile sites even under mild replication stress. Indeed, in cells from patients carrying mutations in the $A T R, B R C A 1$, and FANCD2 genes, higher levels of fragile sites were found (Arlt et al. 2004; Casper et al. 2004; Howlett et al. 2005). Unrepaired DSBs that accumulate at the fragile sites following replication stress in vivo predispose the genome to chromosomal rearrangements that can promote cancer or lead to inherited diseases.

\section{Materials and methods}

Cells, growth conditions, and treatment

HeLa and MCF7 cells were grown in Dulbecco's modified Eagle's medium supplemented with 10\% fetal calf serum. Aphidi- 
colin treatment was performed by growing cells for $24 \mathrm{~h}$ in M-199 media supplemented with 10\% fetal calf serum, containing the indicated aphidicolin concentration and $0.5 \%$ ethanol.

\section{Immunofluorescence}

Cells were fixed in $3.7 \%$ formaldehyde/PBS for $10 \mathrm{~min}$, permeabilized with $0.5 \%$ Triton/PBS, and blocked with 5\% BSA/PBS. The primary antibodies used in this study were mouse and rabbit anti- $\gamma \mathrm{H} 2 \mathrm{AX}$ (Upstate Biotechnology), mouse anti-pT2609 DNA-PKcs (raised in Dr. Chen's laboratory), rabbit anti-Rad51 (Oncogene Research Products), and sheep anti-MDC1 (previously described in Goldberg et al. 2003). Appropriate rhodamine or Cy2 conjugated secondary antibodies were added (Jackson Immunoresearch Laboratories). Images were taken with a BioRad confocal microscope. For focus information analysis at least 50 nuclei for each condition were analyzed.

\section{Chromosome preparation and fragile site analysis}

Cells were harvested after a 40-min treatment with $100 \mathrm{ng} / \mathrm{mL}$ colchicine followed by a 40 -minute incubation in $0.4 \% \mathrm{KCl}$ at $37^{\circ} \mathrm{C}$ and multiple changes of $3: 1$ methanol:acetic acid fixative. Cells were dropped onto slides and slides were baked overnight at $37^{\circ} \mathrm{C}$ before the FISH protocol. BAC clones crossing or within fragile sites were used for FISH analysis. BAC $1 \mathrm{O} 12$ was used for FRA3B and BAC 264L1 was used for FRA16D. Probes were labeled with digoxigenin (DIG)-11-dUTP (Roche) by nick translation. DIG-labeled probes were detected with fluorescein isothiocyanate (FITC)-conjugated sheep anti-DIG specific antibodies (Roche) and the signal was amplified using donkey anti-sheep Cy2 antibodies (Jackson Immunoresearch Laboratories). DNA was stained with propidium iodide. FISH on metaphase chromosomes was performed as previously described (Lichter et al. 1988).

Fragile site expression was analyzed using a Nikon fluorescent microscope. For total gaps and constrictions, at least 50 metaphases for each condition were analyzed. For expression of specific fragile sites, at least 50 hybridizations were analyzed.

\section{RNA interference}

The pSUPER plasmid was used for expressing siRNAs as previously described (Brummelkamp et al. 2002). The sequences used for down-regulating Rad51, DNA-PKcs, and Ligase IV were TG TAGCATATGCTCGAGCG, CTGCAGGCGTATCCAGCAC, and GAGCCTTCTTCAACTTATA, respectively. Transfection of HeLa and MCF7 cells was performed by using an electroporation protocol (described in Agami and Bernards 2000). Aphidicolin treatment was performed $72 \mathrm{~h}$ post-transfection.

\section{Western blot}

Polyacrylamide gels were used for protein separation for detection of DNA-PKcs (5\%), Rad51 (12\%), and Ligase IV (12\%). The gel was transferred to a nitrocellulose or PVDF membrane and antibody hybridization and chemiluminescence were performed according to standard procedures. DNA-PKcs was detected with mouse antibodies (Neomarkers), Rad51 was detected with rabbit antibodies (Novus Biologicals), and Ligase IV was detected with rabbit antibodies kindly provided to us by Professor Stephen P. Jackson (University of Cambridge, Cambridge, UK). HRP-conjugated anti-mouse and anti-rabbit secondary antibodies were obtained from Jackson Immunoresearch Laboratories. The level of protein expression was analyzed using the NIH image software.

\section{Radiation sensitivity assay}

Radiation sensitivity was assessed by the 3-[4, 5-dimethylthiazol-2-yl]-2, 5-diphenyl-tetrazolium bromide (MTT) assay. Cells were seeded in medium in 96-well plates after transfection with the pSUPER plasmid or pSUPER containing the relevant siRNAs. Seventy-two hours post-transfection, cells were irradiated with different doses of irradiation (4-10 Gy) using an X-ray radiation source (Faxitron X-Ray). Seventy-two hours post-irradiation, MTT ( $20 \mu \mathrm{L}$ of a $5 \mathrm{mg} / \mathrm{mL}$ solution in PBS) was added to each well. After $5 \mathrm{~h}$ of incubation at $37^{\circ} \mathrm{C}$, the cells were lysed with $200 \mu \mathrm{L}$ of dimethyl sulfoxide (DMSO), and the absorbance of each well was measured at $535 \mathrm{~nm}$ and $635 \mathrm{~nm}$ by a microplate reader (Tecan).

\section{Statistical analysis}

For comparison of total gaps and constrictions and foci number, the Kolmogorov-Smirnov two-sample test was used. For comparison of specific fragile sites expression, Fisher's test was used.

\section{Immunofluorescence and FISH}

Immunofluorescence and FISH was performed as previously described (Sullivan and Warburton 1999). Briefly, chromosome spreads were obtained by cytocentrifugation (Cytospin 3, Shandon Inc.), followed by detection with specific antibodies against phospho-DNA-PKcs or $\gamma \mathrm{H} 2 \mathrm{AX}$, and by FISH using standard procedures with BAC clone $1 \mathrm{O} 12$ from the FRA3B region and in several experiments also with a plasmid from centromere 3 (pAE0.68), kindly provided to us by Dr. Mariano Rocchi and Dr. Nicoletta Archidiacono (University of Bari, Bari, Italy). DNA was stained with DAPI. Analysis was performed using a Nikon fluorescent microscope. For analysis of $\gamma \mathrm{H} 2 \mathrm{AX}$ and phosphoDNA-PKcs localization, 50 chromosomes 3 were analyzed.

\section{Acknowledgments}

We thank Naomi Melamed-Book for assistance in confocal analyses, Natalie Elia for assistance in Western blot analyses, Irit Baram for analysis of karyotpes of the HeLa and MCF7 cell lines, Moshe Shuker for assistance with the electroporation protocol, Stephen P. Jackson for providing Ligase IV antibodies, and Dr. Mariano Rocchi and Dr. Nicoletta Archidiacono for providing centromere $3 \mathrm{FISH}$ probes. This research was supported by grants from the Ministry of Science and Technology Israel and the Deutsches Krebsforschungszetrum (DKFZ) to B.K., and from the NIH (grant no. CA50519) to D.J.C.

\section{References}

Abraham, R.T. 2001. Cell cycle checkpoint signaling through the ATM and ATR kinases. Genes \& Dev. 15: 2177-2196.

Agami, R. and Bernards, R. 2000. Distinct initiation and maintenance mechanisms cooperate to induce G1 cell cycle arrest in response to DNA damage. Cell 102: 55-66.

Allen, C., Kurimasa, A., Brenneman, M.A., Chen, D.J., and Nickoloff, J.A. 2002. DNA-dependent protein kinase suppresses double-strand break-induced and spontaneous homologous recombination. Proc. Natl. Acad. Sci. 99:37583763.

Arlt, M.F., Miller, D.E., Beer, D.G., and Glover, T.W. 2002. Molecular characterization of FRAXB and comparative common fragile site instability in cancer cells. Genes Chromo- 
somes Cancer 33: 82-92.

Arlt, M.F., Casper, A.M., and Glover, T.W. 2003. Common fragile sites. Cytogenet. Genome Res. 100: 92-100.

Arlt, M.F., Xu, B., Durkin, S.G., Casper, A.M., Kastan, M.B., and Glover, T.W. 2004. BRCA1 is required for common-fragilesite stability via its G2/M checkpoint function. Mol. Cell. Biol. 24: 6701-6709.

Arnaudeau, C., Lundin, C., and Helleday, T. 2001. DNA doublestrand breaks associated with replication forks are predominantly repaired by homologous recombination involving an exchange mechanism in mammalian cells. J. Mol. Biol. 307: 1235-1245.

Bassing, C.H. and Alt, F.W. 2004. H2AX may function as an anchor to hold broken chromosomal DNA ends in close proximity. Cell Cycle 3: 149-153.

Baumann, P. and West, S.C. 1998. Role of the human RAD51 protein in homologous recombination and double-strandedbreak repair. Trends Biochem. Sci. 23: 247-251.

Brummelkamp, T.R., Bernards, R., and Agami, R. 2002. A system for stable expression of short interfering RNAs in mammalian cells. Science 296: 550-553.

Burma, S. and Chen, D.J. 2004. Role of DNA-PK in the cellular response to DNA double-strand breaks. DNA Repair (Amst.) 3: 909-918.

Callahan, G., Denison, S.R., Phillips, L.A., Shridhar, V., and Smith, D.I. 2003. Characterization of the common fragile site FRA9E and its potential role in ovarian cancer. Oncogene 22: 590-601.

Casper, A.M., Nghiem, P., Arlt, M.F., and Glover, T.W. 2002. ATR regulates fragile site stability. Cell 111: 779-789.

Casper, A.M., Durkin, S.G., Arlt, M.F., and Glover, T.W. 2004. Chromosomal instability at common fragile sites in seckel syndrome. Am. J. Hum. Genet. 75: 654-660.

Cha, R.S. and Kleckner, N. 2002. ATR homolog Mec1 promotes fork progression, thus averting breaks in replication slow zones. Science 297: 602-606.

Chan, D.W., Chen, B.P., Prithivirajsingh, S., Kurimasa, A., Story, M.D., Qin, J., and Chen, D.J. 2002. Autophosphorylation of the DNA-dependent protein kinase catalytic subunit is required for rejoining of DNA double-strand breaks. Genes \& Dev. 16: 2333-2338.

Chen, B.P., Chan, D.W., Kobayashi, J., Burma, S., Asaithamby, A., Morotomi-Yano, K., Botvinick, E., Qin, J., and Chen, D.J. 2005. Cell cycle dependence of DNA-PK phosphorylation in response to DNA double strand breaks. J. Biol. Chem. 280: 14709-14715.

Cheng, C.H. and Kuchta, R.D. 1993. DNA polymerase $\varepsilon$ : Aphidicolin inhibition and the relationship between polymerase and exonuclease activity. Biochemistry 32: 85688574.

Critchlow, S.E. and Jackson, S.P. 1998. DNA end-joining: From yeast to man. Trends Biochem. Sci. 23: 394-398.

Denison, S.R., Callahan, G., Becker, N.A., Phillips, L.A., and Smith, D.I. 2003. Characterization of FRA6E and its potential role in autosomal recessive juvenile parkinsonism and ovarian cancer. Genes Chromosomes Cancer 38: 40-52.

Fang, J.M., Arlt, M.F., Burgess, A.C., Dagenais, S.L., Beer, D.G., and Glover, T.W. 2001. Translocation breakpoints in FHIT and FRA3B in both homologs of chromosome 3 in an esophageal adenocarcinoma. Genes Chromosomes Cancer 30: 292298.

Ferber, M.J., Thorland, E.C., Brink, A.A., Rapp, A.K., Phillips, L.A., McGovern, R., Gostout, B.S., Cheung, T.H., Chung, T.K., Fu, W.Y., et al. 2003. Preferential integration of human papillomavirus type 18 near the c-myc locus in cervical carcinoma. Oncogene 22: 7233-7242.
Glover, T.W., Berger, C., Coyle, J., and Echo, B. 1984. DNA polymerase $\alpha$ inhibition by aphidicolin induces gaps and breaks at common fragile sites in human chromosomes. Hum. Genet. 67: 136-142.

Goldberg, M., Stucki, M., Falck, J., D'Amours, D., Rahman, D., Pappin, D., Bartek, J., and Jackson, S.P. 2003. MDC1 is required for the intra-S-phase DNA damage checkpoint. $\mathrm{Na}$ ture 421: 952-956.

Hecht, F. and Hecht, B.K. 1984. Fragile sites and chromosome breakpoints in constitutional rearrangements. I. Amniocentesis. Clin. Genet. 26: 169-173.

Hellman, A., Rahat, A., Scherer, S.W., Darvasi, A., Tsui, L.C., and Kerem, B. 2000. Replication delay along FRA7H, a common fragile site on human chromosome 7 , leads to chromosomal instability. Mol. Cell. Biol. 20: 4420-4427.

Hellman, A., Zlotorynski, E., Scherer, S.W., Cheung, J., Vincent, J.B., Smith, D.I., Trakhtenbrot, L., and Kerem, B. 2002. A role for common fragile site induction in amplification of human oncogenes. Cancer Cell 1: 89-97.

Howlett, N.G., Taniguchi, T., Durkin, S.G., D'Andrea, A.D., and Glover, T.W. 2005. The Fanconi anemia pathway is required for the DNA replication stress response and for the regulation of common fragile site stability. Hum. Mol. Genet. 14: 693-701.

Ikegami, S., Taguchi, T., Ohashi, M., Oguro, M., Nagano, H., and Mano, Y. 1978. Aphidicolin prevents mitotic cell division by interfering with the activity of DNA polymerase- $\alpha$. Nature 275: 458-460.

Jackson, S.P. 2002. Sensing and repairing DNA double-strand breaks. Carcinogenesis 23: 687-696.

Khanna, K.K. and Jackson, S.P. 2001. DNA double-strand breaks: Signaling, repair and the cancer connection. Nat. Genet. 27: 247-254.

Krummel, K.A., Roberts, L.R., Kawakami, M., Glover, T.W., and Smith, D.I. 2000. The characterization of the common fragile site FRA16D and its involvement in multiple myeloma translocations. Genomics 69: 37-46.

Krummel, K.A., Denison, S.R., Calhoun, E., Phillips, L.A., and Smith, D.I. 2002. The common fragile site FRA16D and its associated gene WWOX are highly conserved in the mouse at Fra8E1. Genes Chromosomes Cancer 34: 154-167.

Le Beau, M.M., Rassool, F.V., Neilly, M.E., Espinosa III, R., Glover, T.W., Smith, D.I., and McKeithan, T.W. 1998. Replication of a common fragile site, FRA3B, occurs late in S phase and is delayed further upon induction: Implications for the mechanism of fragile site induction. Hum. Mol. Genet. 7: 755-761.

Lemoine, F.J., Degtyareva, N.P., Lobachev, K., and Petes, T.D. 2005. Chromosomal translocations in yeast induced by low levels of DNA polymerase a model for chromosome fragile sites. Cell 120: 587-598.

Lichter, P., Cremer, T., Borden, J., Manuelidis, L., and Ward, D.C. 1988. Delineation of individual human chromosomes in metaphase and interphase cells by in situ suppression hybridization using recombinant DNA libraries. Hum. Genet. 80: 224-234.

Limongi, M.Z., Pelliccia, F., and Rocchi, A. 2003. Characterization of the human common fragile site FRA2G. Genomics 81: 93-97.

Lou, Z., Chen, B.P., Asaithamby, A., Minter-Dykhouse, K., Chen, D.J., and Chen, J. 2004. MDC1 regulates DNA-PK autophosphorylation in response to DNA damage. I. Biol. Chem. 279: 46359-46362.

Lukas, C., Melander, F., Stucki, M., Falck, J., Bekker-Jensen, S., Goldberg, M., Lerenthal, Y., Jackson, S.P., Bartek, J., and Lukas, J. 2004. Mdc1 couples DNA double-strand break rec- 
ognition by Nbs1 with its H2AX-dependent chromatin retention. EMBO J. 23: 2674-2683.

Lundin, C., Erixon, K., Arnaudeau, C., Schultz, N., Jenssen, D., Meuth, M., and Helleday, T. 2002. Different roles for nonhomologous end joining and homologous recombination following replication arrest in mammalian cells. Mol. Cell. Biol. 22: 5869-5878.

Michel, B., Flores, M.J., Viguera, E., Grompone, G., Seigneur, M., and Bidnenko, V. 2001. Rescue of arrested replication forks by homologous recombination. Proc. Natl. Acad. Sci. 98: 8181-8188.

Mills, K.D., Ferguson, D.O., Essers, J., Eckersdorff, M., Kanaar, R., and Alt, F.W. 2004. Rad54 and DNA Ligase IV cooperate to maintain mammalian chromatid stability. Genes \& Dev. 18: $1283-1292$.

Mishmar, D., Rahat, A., Scherer, S.W., Nyakatura, G., Hinzmann, B., Kohwi, Y., Mandel-Gutfroind, Y., Lee, J.R., Drescher, B., Sas, D.E., et al. 1998. Molecular characterization of a common fragile site (FRA7H) on human chromosome 7 by the cloning of an SV40 integration site. Proc. Natl. Acad. Sci. 95: 8141-8146.

Mishmar, D., Mandel-Gutfreund, Y., Margalit, H., and Kerem, B. 1999. Common fragile sites: G-Band characteristics within an R-band. Am. J. Hum. Genet. 64: 908-910.

Musio, A., Montagna, C., Mariani, T., Tilenni, M., Focarelli, M.L., Brait, L., Indino, E., Benedetti, P.A., Chessa, L., Albertini, A., et al. 2005. Smc1 involvement in fragile site expression. Hum. Mol. Genet. 14: 525-533.

Palakodeti, A., Han, Y., Jiang, Y., and Le Beau, M.M. 2004. The role of late/slow replication of the FRA16D in common fragile site induction. Genes Chromosomes Cancer 39: 71-76.

Paull, T., Rogakou, E.P., Yamazaki, V., Kirchgessner, C.U., Gellert, M., and Bonner, W.M. 2000. A critical role for histone $\mathrm{H} 2 \mathrm{AX}$ in recruitment of repair factors to nuclear foci after DNA damage. Curr. Biol. 10: 886-895.

Rapp, A. and Greulich, K.O. 2004. After double-strand break induction by UV-A, homologous recombination and nonhomologous end joining cooperate at the same DSB if both systems are available. J. Cell Sci. 117: 4935-4945.

Richards, R.I. 2001. Fragile and unstable chromosomes in cancer: Causes and consequences. Trends Genet. 17: 339-345.

Richardson, C. and Jasin, M. 2000. Coupled homologous and nonhomologous repair of a double-strand break preserves genomic integrity in mammalian cells. Mol. Cell. Biol. 20: 9068-9075.

Rogakou, E.P., Pilch, D.R., Orr, A.H., Ivanova, V.S., and Bonner, W.M. 1998. DNA double-stranded breaks induce histone H2AX phosphorylation on serine 139. J. Biol. Chem. 273: 5858-5868.

Rogakou, E.P., Boon, C., Redon, C., and Bonner, W.M. 1999. Megabase chromatin domains involved in DNA doublestrand breaks in vivo. J. Cell Biol. 146: 905-916.

Rozier, L., El-Achkar, E., Apiou, F., and Debatisse, M. 2004. Characterization of a conserved aphidicolin-sensitive common fragile site at human 4q22 and mouse 6C1: Possible association with an inherited disease and cancer. Oncogene 23: 6872-6880.

Ruiz-Herrera, A., Garcia, F., Fronicke, L., Ponsa, M., Egozcue, J., Caldes, M.G., and Stanyon, R. 2004. Conservation of aphidicolin-induced fragile sites in Papionini (Primates) species and humans. Chromosome Res. 12: 683-690.

Saintigny, Y., Delacote, F., Vares, G., Petitot, F., Lambert, S., Averbeck, D., and Lopez, B.S. 2001. Characterization of homologous recombination induced by replication inhibition in mammalian cells. EMBO J. 20: 3861-3870.

Shiraishi, T., Druck, T., Mimori, K., Flomenberg, J., Berk, L.,
Alder, H., Miller, W., Huebner, K., and Croce, C.M. 2001. Sequence conservation at human and mouse orthologous common fragile regions, FRA3B/FHIT and Fra14A2/Fhit. Proc. Nat1. Acad. Sci. 8: 5722-5727.

Stewart, G.S., Wang, B., Bignell, C.R., Taylor, A.M., and Elledge, S.J. 2003. MDC1 is a mediator of the mammalian DNA damage checkpoint. Nature 421: 961-966.

Sullivan, B.A. and Warburton, P.E. 1999. Studying the progression of vertebrate chromosomes through mitosis by immunofluorescence and FISH. In Chromosomes structural analysis: A practical approach (ed. W.A. Bickmore) pp. 81-101. Oxford University Press.

Sutherland, G.R. 2003. Rare fragile sites. Cytogenet. Genome Res. 100: $77-84$.

Tarsounas, M., Davies, A.A., and West, S.C. 2004. RAD51 localization and activation following DNA damage. Philos. Trans. R. Soc. Lond. B Biol. Sci. 359: 87-93.

Thorland, E.C., Myers, S.L., Persing, D.H., Sarkar, G., McGovern, R.M., Gostout, B.S., and Smith, D.I. 2000. Human papillomavirus type 16 integrations in cervical tumors frequently occur in common fragile sites. Cancer Res. 1: 59165921.

Thorland, E.C., Myers, S.L., Gostout, B.S., and Smith, D.I. 2003. Common fragile sites are preferential targets for HPV16 integrations in cervical tumors. Oncogene 22: 1225-1237.

Tibbetts, R.S., Cortez, D., Brumbaugh, K.M., Scully, R., Livingston, D., Elledge, S.J., and Abraham, R.T. 2000. Functional interactions between BRCA1 and the checkpoint kinase ATR during genotoxic stress. Genes \& Dev. 14: 2989-3002.

Wang, L., Darling, J., Zhang, J.S., Huang, H., Liu, W., and Smith, D.I. 1999. Allele-specific late replication and fragility of the most active common fragile site, FRA3B. Hum. Mol. Genet. 8: 431-437.

Ward, I.M. and Chen, J. 2001. Histone H2AX is phosphorylated in an ATR-dependent manner in response to replicational stress. J. Biol. Chem. 276: 47759-47762.

Weterings, E. and van Gent, D.C. 2004. The mechanism of nonhomologous end-joining: A synopsis of synapsis. DNA Repair 3: 1425-1435.

Wilke, C.M., Guo, S.W., Hall, B.K., Boldog, F., Gemmill, R.M., Chandrasekharappa, S.C., Barcroft, C.L., Drabkin, H.A., and Glover, T.W. 1994. Multicolor FISH mapping of YAC clones in 3p14 and identification of YAC spanning both FRA3B and the $t(3 ; 8)$ associated with hereditary renal cell carcinoma. Genomics 22: 319-326.

Wilke, C.M., Hall, B.K., Hoge, A., Pardee, W., Smith, D.I., and Glover, T.W. 1996. FRA3B extends over a broad region and contains a spontaneous HPV16 integration site: Direct evidence for the coincidence of viral integration sites and fragile sites. Hum. Mol. Genet. 5: 187-195.

$\mathrm{Xu}, \mathrm{X}$. and Stern, D.F. 2003. NFBD1/KIAA0170 is a chromatinassociated protein involved in DNA damage signaling pathways. J. Biol. Chem. 278: 8795-8803.

$\mathrm{Xu}$, B., Kim, S., and Kastan, M.B. 2001. Involvement of Brcal in S-phase and $\mathrm{G}_{2}$-phase checkpoints after ionizing irradiation. Mol. Cell. Biol. 21: 3445-3450.

Xu, B., O’Donnell, A.H., Kim, S.T., and Kastan, M.B. 2002. Phosphorylation of serine 1387 in Brcal is specifically required for the Atm-mediated S-phase checkpoint after ionizing irradiation. Cancer Res. 62: 4588-4591.

Yunis, J.J. and Soreng, A. 1984. Constitutive fragile sites and cancer. Science 226: 1199-1204.

Zlotorynski, E., Rahat, A., Skaug, J., Ben-Porat, N., Ozeri, E., Hershberg, R., Levi, A., Scherer, S.W., Margalit, H., and Kerem, B. 2003. Molecular basis for expression of common and rare fragile sites. Mol. Cell. Biol. 23: 7143-7151. 


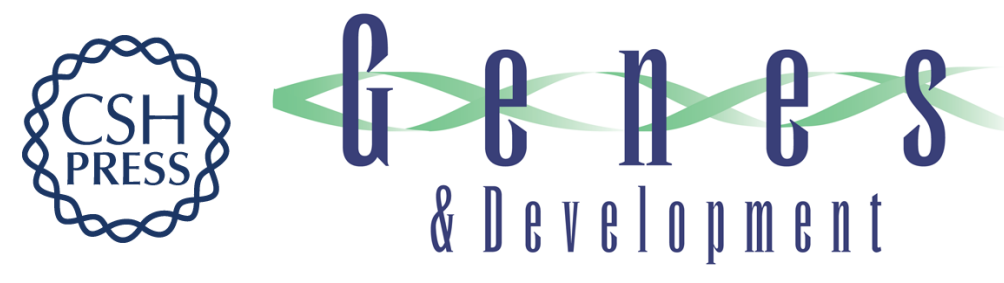

\section{Homologous recombination and nonhomologous end-joining repair pathways regulate fragile site stability}

Michal Schwartz, Eitan Zlotorynski, Michal Goldberg, et al.

Genes Dev. 2005, 19:

Access the most recent version at doi:10.1101/gad.340905

Supplemental
Material http://genesdev.cshlp.org/content/suppl/2005/10/27/19.22.2715.DC1

References This article cites 70 articles, 26 of which can be accessed free at:

http://genesdev.cshlp.org/content/19/22/2715.full.html\#ref-list-1

License

Email Alerting

Receive free email alerts when new articles cite this article - sign up in the box at the top

Service

right corner of the article or click here.

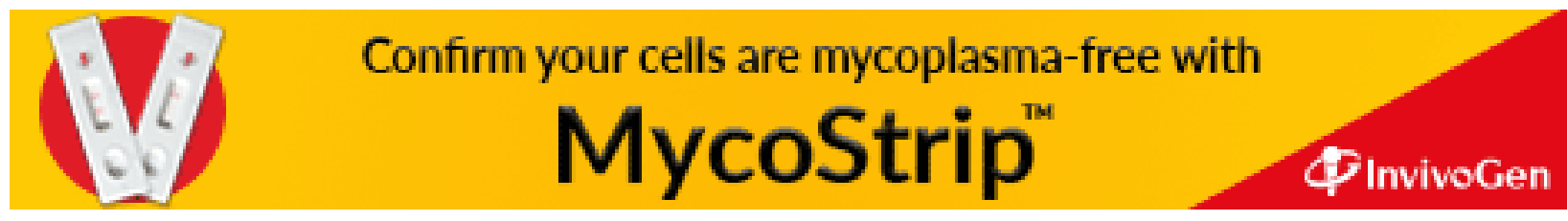

